\title{
Formação de Professores Indígenas, contextualizando o ensino às práticas culturais da etnia Satere-Mawe
}

\author{
Formation of Indigenous Teachers, contextualizing the teaching of the cultural \\ practices of the ethnic Satere-Mawe
}

\author{
Vilma de Jesus de Almeida Serra (iD https://orcid.org/0000-0001-5490-3406 \\ Instituto Federal de Ciência e Tecnologia do Amazonas - IFAM \\ E-mail: vilma.serra@ifam.edu.br \\ Carlos Dinely Esteves (D) https://orcid.org/0000-0003-3809-5810 \\ Universidade do Estado do Amazonas - UEA \\ E-mail: Carloswaham@gmail.com
}

\section{Resumo}

Este trabalho trata sobre a formação de professores da etnia Satere-Mawe, apresentando reflexões sobre as experiências construídas no diálogo entre atividade de pesquisa etnográfica com viés sobre a cosmologia presente na escola indígena e atividade de extensão como um trabalho de cunho social, conhecendo a escola indígena em seu território. A pesquisa propôs uma investigação qualitativa, que procurou conhecer as experiências pedagógicas dos professores e os anseios dos tuxauas no que se refere ao ensino na etnia que habita o rio Marau, na cidade Maués/AM. O resultado da pesquisa culminou em proposta de extensão com duração de dois anos e, sua análise, a escrita do presente artigo. Em sua estrutura textual, destacamos algumas considerações sobre aspectos do cotidiano da etnia presentes na escola. Por isso, os temas tratados permitiram fomentar um diálogo com as práticas culturais desta etnia com o intuito de projetar novas reflexões a respeito da realidade dos Satere-Mawe. Compreendeu-se com a observação empírica aspectos como: a relação do contexto social SatereMawe, cultura e etnoconhecimento, além do detalhamento das práticas vivenciadas nas escolas de duas comunidades. A trajetória metodológica baseou-se nos seguintes princípios norteadores: realização de oficinas e fortalecimento da cultura local através de narrativas orais e trocas de saberes. Este trabalho mostra que é possível contribuir com a formação de professores em sua comunidade.

Palavras-chave: Formação de Professores. Etnia. Cultura.

\begin{abstract}
This paper talks about the teachers training of the Satere-Mawe ethnic, presenting reflections about experiences built on dialogue between ethnographic research activities with a bias about cosmetology present at the indigenous school and the extension activity as a social nature work, knowing the indigenous school in its territory. The research proposed a qualitative investigation, which looked for to know the teacher's pedagogical experiences and the yearning of the tuxauas in what refers to teaching in the ethnicity that inhabits the Marau River, in the city of Maués/AM. The research result culminated in a two-year extension proposal and, in its analysis, the writing of this article. In its textual structure, we highlight some considerations about aspects of the daily life of the ethnicity present in the school. That
\end{abstract}


is why the treated themes allowed fomenting a dialogue with the cultural practices of this ethnicity with an intention to project new reflections of regard on the reality of the Satere-Mawe. We realize, under empirical observation, aspects such as the relation of Satere-Mawe social context, culture and ethnoknowledge, beyond the detailing of the lived practices in schools of two communities. The methodological path based on the guiding orienting principles: holding of workshops and strengthening local culture through oral narratives and exchanges of knowledge. This paper shows that it is possible to contribute to the teacher training in its community.

Keywords: Teacher training. Ethnicity. Culture

\section{Introdução}

Este artigo aponta o resultado de atividade de extensão e de pesquisa do Instituto Federal de Educação, Ciência e Tecnologia do Amazonas (IFAM) Campus Maués, com o objetivo de propor uma formação continuada na perspectiva de valorizar a escola indígena e a cultura local, principalmente, do sujeito histórico Satere-Mawe, a fim de compreender as relações sociais e históricas da etnia que precisam ser fortalecidas no cotidiano da comunidade. Para isso, realizamos uma reflexão do etnoconhecimento presente nas suas práticas culturais. Consideraram-se certos aspectos do cotidiano da etnia presentes na escola indígena e suas práticas culturais no contexto atual.

A proposta metodológica visou articular atividade pedagógica, na realização de oficinas, a fim de interagir com os saberes dos professores e dos tuxauas ou tu'isas. Para coleta de dados, optou-se pela pesquisa qualitativa associada à pesquisa do tipo etnográfica com observação participante, descrevendo o processo educativo dos sujeitos e alguns elementos de sua cultura. Segundo André (1995, p.28) "A observação é chamada participante, porque parte do princípio de que o pesquisador tem sempre um grau de interação com a situação estudada, afetando-a e sendo por ela afetado". Sendo esta relação entre escola e comunidade que iremos apresentar, nas próximas linhas, uma pequena parte da riqueza que nos foi concedida neste contato.

Este artigo dialoga com Objetivo de Desenvolvimento Sustentável (ODS) 4 da Agenda 2030, que pretende "Assegurar a educação inclusiva e equitativa, e promover oportunidade de aprendizagem ao longo da vida para todos" Dossiê (2019). Segundo a Agenda 2030, cabe aos governos dos países envolvidos, promover e implementar os objetivos e as metas nos âmbitos globais, nacionais, regionais e locais, com desenvolvimento de projetos e ações que possam contribuir para concretização desses objetivos.

A organização textual deste trabalho está estruturada na seguinte maneira: iniciamos com uma abordagem sobre as características e a construção dos saberes entre os Satere-Mawe, numa reflexão sobre o etnoconhecimento presente no Ritual da Tucandeira e o Mito do Guaraná. Em seguida, detalhamos a trajetória metodológica das oficinas nas duas comunidades São Pedro e Terra Nova no rio Marau. Por fim, descrevemos os resultados e discussões das atividades, no intuito de demonstrar as observações e experiências na escola indígena.

A etnia Satere-Mawe ocupava, tradicionalmente, a bacia dos rios Tapajós, Madeira e Amazonas e que, em razão de invasão de seu território, passou a ocupar as cabeceiras dos rios Marau e Andirá. O município de Maués possui uma tradição construída, ao logo dos anos, pelo contato com esta etnia que tem o guaraná como 
símbolo semiótico o qual dá sentido à representação identitária do grupo. Constrói-se a identidade com a possibilidade de revelação do inexplicável. Origina-se o grupo dentro de uma situação atemporal e acima de tudo de maneira sagrada. Neste sentido, a origem é parte de um todo que não pode existir separado entre si.

No Mito de Origem deste povo, é descrita a relação de um relato sagrado em um espaço mítico ligado à realidade em que o mito é representado e contextualizado através das narrativas. É dentro dessa dimensão que a etnia constrói sua identidade, dentro de um processo histórico e social. O guaraná é ligado ao fenômeno cosmogônico, em que o mito do guaraná dá origem a esta etnia, tendo como aspecto humano, o próprio fruto que apresenta traços semelhantes ao olho humano.

Isso nos leva a considerar que a mitologia influencia as práticas sociais no cotidiano, visto que o Mito é narrado através do que existe como reflexo do mundo cultural. Dentro dessa dimensão, pode-se afirmar que a convivência seria a representação simbólica, consolidando a existência desses sujeitos como filhos do guaraná. Segundo Teixeira (2005, p.130) eles são "os inventores da cultura do guaraná, já que [...] criaram a técnica para seu beneficiamento, tornando possível que muitos conheçam e consumam o guaraná no Brasil e no exterior".

Isso ocorre pelo fato de a cultura do guaraná ser parte da construção étnica, visto que o guaraná simboliza a identidade da etnia. Não se pode falar dos Satere-Mawe, sem antes reconhecer que a prática cultural de se produzir e consumir o guaraná é algo específico desse grupo. Por conta desse aspecto, pode-se identificá-los como sujeito Satere-Mawe.

\section{Cultura, etnoconhecimento e as práticas sociais dos Satere-Mawe}

Quando se trata de etnoconhecimento, significa considerar que a sabedoria de uma sociedade se constrói no cotidiano, desde as informações mais simples às mais complexas. Esse processo de construção de conhecimento é resultado da compreensão do sujeito sobre si e o mundo através de suas práticas sociais. Tal processo revela 0 ato constante de se autoidentificar no seu espaço e na sua realidade.

Todo sujeito é histórico pelo fato de construir e transmitir conhecimentos de sua cultura. Assimilamos as práticas sociais através das relações com os nossos familiares e os sujeitos que convivemos e nos relacionamos no dia a dia, tanto na aquisição da linguagem quanto dos valores e das tradições da sociedade que pertencemos. Nesse aspecto, percebe-se que toda formação étnica constrói-se no decorrer das nossas relações sociais e dos conhecimentos que assimilamos e construímos.

$\mathrm{Na}$ verdade, o etnoconhecimento representa muitas vezes algo que a nossos olhos não tem muita importância, é algo que não apresenta com grandes significados para aquele que observa. Seria o que Lévi-Strauss (1989, p.19) vai identificar quando afirma que "[...] Mesmo uma criança pode muitas vezes identificar a espécie de uma árvore a partir de um mínimo fragmento de madeira". A partir desta reflexão sobre o etnoconhecimento, o autor afirma que todo conhecimento construído por uma etnia deve ser reconhecido como uma ciência primeira, e não como uma ciência primária.

É importante considerar que os valores étnicos se constroem não só dentro de um processo de interpretação das práticas culturais de uma etnia, mas também nas 
relações iterétnicas que dão significado a tudo que se produz como conhecimento. Segundo (CUNHA, 2009) a "Cultura" se constrói nos encontros e nas relações iterétnicas dos vários grupos que habitavam a Amazônia. Isso se comprova na afirmação dos autores Spix e Martius (1981) que detalham as relações dos SatereMawe entre as etnias mundurukus, muras e tupinambás, isso muito antes dos aldeamentos na Amazônia. Como exemplo mais próximo de etnoconhecimento dos Satere-Mawe, podemos citar o Mito da Tucandeira. Visto que os relatos informam sobre as lutas, as guerras e o poder mágico do mito que se consolida ao se revelar como fonte viva de uma prática religiosa o qual fundamenta o mito de passagem para a vida adulta. Esses relatos são cantados e demonstrados aos ferroados como convite a ouvir tudo aquilo que se sabe sobre o mito e a trajetória de vida do grupo e da entidade espiritual responsável para transmitir e dirigir o ritual.

Percebe-se que o ritual reconstrói acontecimentos passados que devem ser conhecidos e transmitidos para as novas gerações da etnia, como algo simbólico que fortalece suas práticas culturais. As narrativas são cantadas a qual revela o Tatu como a entidade que vem trazer o ritual para todos aqueles que necessitam ser ferroados (crianças e adolescentes do sexo masculino que depois do ritual estão preparados para vida adulta) e com isso se tornam mais fortes diante de sua realidade. Segundo Martius e Spix (1981, p.80), este ritual Ihes foi contado em língua tupi, ou seja, quando "o menino mawé completa oito ou nove anos de idade, os comunitários o vestem com mangas de algodão que podem ser amarradas em cima e embaixo das mãos, uma espécie de luva, cheias de formigas tucandeiras [...]". Então, reúnem-se os vizinhos para tomarem caxiri e iniciar o canto

[...] Logo que o rapaz, sofrendo atrozmente, começa a berrar e a queixar-se, o bando faz roda em torno dele, e dança, jubila, e anima-o até o pequeno cair exausto no chão. É ele então entregue, com as extremidades terrivelmente inchadas, às velhas, para o tratarem com aplicação de suco fresco de folha de mandioca. Quando o menino de novo recupera as forças, começa a experimentar quando pode retesar o arco. Estas cerimônias bárbaras são continuadas até a idade de quatorze anos; quando o rapaz aprende a suportar a dor, sem dar sinal de sofrimento, é emancipado e pode casar-se" (MARTIUS; SPIX, 1981, p.28).

O canto manifesta o convite ao ritual no ritmo de festa, explicando de onde surge esse encontro festivo. O convite se faz presente para todo aquele que se sente parte de uma história cantada que revela o significado de uma identidade. Essa identidade é histórica e cantada para se fundamentar na revelação de uma dor para o reconhecimento de uma história de lutas e, sobretudo, das entidades que recriam o mundo espiritual que recompõe o som revelado sobre uma agonia de coragem.

O Mito da Tucandeira possibilita ao sujeito da cultura Satere-Mawe vincular-se a um passado remoto, mas que se faz presente no cotidiano. Esse cotidiano é renovado com as narrativas cantadas. Como já afirmamos, reconhece-se com o mito e a história do povo e a sua identidade. Assim, revive-se uma história não somente de dores das ferroadas, mas de um passado revelador daquilo que é a identidade Satere-Mawe.

Tais colocações nos levam a considerar que o conhecimento ou etnoconhecimento é manifestado em grupo, como um processo de humanização. Humanizamo-nos em relação com o outro e com a realidade que nos cerca. Este ato está no palco do cotidiano no qual, dentro de sua complexidade, identifica-se como o elemento 
primordial de nossa identidade em sociedade. Neste sentido, o ato de conhecer é algo indispensável para que um grupo social construa sua identidade, pois todo sujeito se revela naquilo que faz e constrói no seu cotidiano.

Sobre este aspecto, podemos citar outro exemplo da cultura Satere-Mawe, o ritual do Sapó ${ }^{1}$, o qual revela a força da palavra na transmissão de conhecimento e crença. Seria o sinônimo da continuidade daquilo que se fala e que se tornará real. Nesse sentido, seja os Satere-Mawe da comunidade São Pedro ou da comunidade Terra Nova, em que buscam dentro de uma crença comum, reviver a prática cultural de renovação da palavra como expressão religiosa.

A prática de tomar, todos os dias em jejum, o warana, que significa guaraná em língua portuguesa, retrata o surgimento do povo, e por isso, revela-se o que o sujeito SatereMawe é enquanto se alimenta. Identifica-se uma prática reveladora do que se é e do que poderá ser aqueles que tomam e dialogam com o warana. Em outras palavras, essa dinamicidade é construída como diálogo sobre o que é manifestado entre os que vivem sua cultura a partir de um caráter dialógico reflexivo. Todo diálogo é carregado de símbolos que dão sentido e forma em toda e qualquer expressão cultural.

A riqueza da cultura Satere-Mawe dentro desse processo de transmissão de tudo o que esses sujeitos comunicam com o seu cotidiano, mostrando um diálogo prático o qual representa o Mito do Guaraná a partir do momento que for ingerida a bebida. Bebe-se o guaraná para que a fala possa enraizar as palavras que darão sentido e razão à vida e ao trabalho do dia a dia. O Mito serve como elemento sagrado em tudo que diz na presença do $t u^{\prime} i s a^{2}$. Esse ato de beber dever ser repetido, não pode ser ímpar, é necessário formar o número par, assim como são pares os membros do nosso corpo e os nossos olhos.

Na figura 01 - Imagem do fruto do guaraná

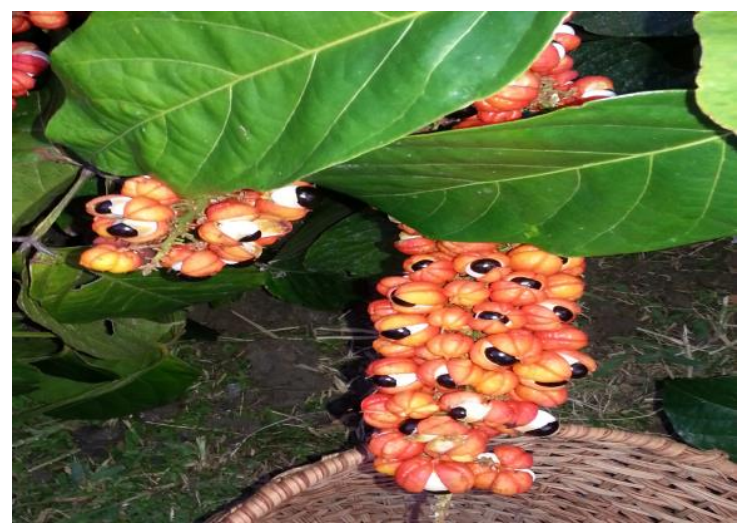

Fonte: Autoria própria (2016).

Assim, podemos concluir como parte de nossa reflexão, que todo ser humano assimila elementos presentes na tradição de sua sociedade através da interação e convivência social com seus membros. É esse sujeito histórico carregado de padrões sociais que nos possibilita refletir sobre a diversidade presente em toda cultura. Partindo dessas considerações, vale ressaltar que nosso trabalho levou em conta a complexidade

\footnotetext{
1 Sapó é o guaraná ralado na pedra queimada e preparado para beber em grupo.

${ }^{2}$ Tu'isa: termo Sateré-Mawé que tem como significado em língua portuguesa, tuxaua, o líder o qual tem como referência de liderança o warana, que em português significa guaraná. (DIÁRIO DE CAMPO DO PRÓPRIO AUTOR, 2016, p. 5).
} 
desta etnia.

\section{Práticas vivenciadas nas comunidades indígenas}

O percurso para chegar até a área indígena tinha a velocidade restrita da canoa com o motor Rabeta e foi dentro dessa construção de possibilidades de interagir como o local, que chegamos e presenciamos a arquitetura típica das casas de palha, onde os tipitis enrolados sobre as cozinhas e dos roçados se destacavam a certeza de que é possível construir novos conhecimentos. A casa de madeira ou de taipa, coberta de palha, entrelaçava-se com o desejo de identificar as tecelagens mais antigas que, por ventura, ainda estavam ali diante dos olhos, uma prática de construção milenar se manifestando diante de todo aquele que deseja reconhecer uma imagem de um produto de conhecimento, tão esquecido no decorrer do tempo.

Também, como fruto da relação com o não-índio, foi possível perceber o uso de roupas, panelas industrializadas, etc. Com isso, foi possível perceber que por mais que os Satere-Mawe estejam há mais de três séculos e meio em relação de desvantagens com os brancos, ainda mantém a língua, como também ainda constroem alguns instrumentos de sua cultura material, como a peneira, tipiti, colares, redes tecidas com algodão, etc.

Sabemos que diante de toda relação entre duas culturas, sempre se assimilam as práticas da outra, no entanto, é importante levar em conta que a cultura mais forte sobrepõe sobre a mais fraca. Por exemplo: a cultura do não-índio possui instituições como a polícia, hospitais, escolas entre outras. No caso dos Satere-Mawe e outros grupos étnicos da Amazônia, eles possuem estruturas complexas com a linguística, cosmologias, organizações sociais e de parentesco, além de normas que representam os clãs, seguidas da cultura material. Porém, dentro desse contexto, sempre os povos nativos da Amazônia estiveram em desvantagens no decorrer das relações com o branco.

Apesar das Leis e das mudanças nas Legislações no que se refere à Educação Indígena em priorizarem o ensino dentro da cultura e da tradição indígena, na prática, ainda percebemos a necessidade de buscar alternativas coerentes para a valorização do sujeito Satere-Mawe dentro sua comunidade. Quando se trata de busca de alternativas, é importante considerar que apesar da escola ser um instrumento de branco, pode-se ser utilizada de maneira diferenciada, tendo como ponto de partida a cultura deste povo.

É óbvio que quando se propõe uma prática pedagógica a partir da estrutura do branco, é provável que mais servirá para manter a dominação, do que para fortalecer a identidade da etnia, no entanto, é possível construir propostas que venham abrir espaço para um ensino dentro de uma relação intercultural produtiva no processo de construção de conhecimento.

O plano ação do projeto partiu da seguinte indagação: como identificar a amplitude da escola indígena como um dos meios para construir alternativas de melhoria, quando se trata da construção de conhecimentos sistematizados? O resultado apontou que é possível, com o diálogo com a cultura indígena, que há cinco séculos, ainda tem como referência a escola do branco, com algumas exceções mais atuais, através dos movimentos étnicos e na formação pedagógica dos professores indígenas. A fim de minimizar o abandono de tantas esperanças infantis que frequentam a escola indígena. Espera-se que esse texto, possibilite novas discussões sobre a problemática 
aqui apresentada. Como afirma Ramos (2018, p. 3).

[...] que naturalmente desafia a escola, especialmente se o trabalho pedagógico adota perspectiva que frisa ser importante considerar os contextos culturais dos alunos, mas não cair no extremo do relativismo - a socialização é uma chave de entendimento da complexa interação entre as afirmações individuais dos alunos que remetem às suas culturas de origens e à prática institucional que orienta o processo de ensino e aprendizagem, sendo essa a ocorrer os valores mais amplamente difundidos de uma determinada sociedade.

Desse modo, os Institutos Federais e as Universidades podem, de forma mais sistematizada, contribuir com processos educativos, abordando em suas práticas de ensino, pesquisa e extensão temas que tratem sobre a cultura étnica, além de mais formação inicial e continuada para professores indígenas. Segundo Teixeira (2005, p.37), os professores da área indígena Andirá-Marau participaram do projeto PiraYawara com o objetivo de cumprir a Lei 93/94 de 1996, a além de habilitá-los como "[...] pesquisadores de sua cultura, fazendo-os aliados do meio ambiente em que vivem. Esse caráter pedagógico torna a educação diferenciada". Como afirma Gersem

[...] o caráter social da instituição escolar e o caráter dinâmico das sociedades humanas, dentre elas, as sociedades indígenas cujas culturas estão em constantes mudanças e atualizações. Não há nada de estranho, portanto, que a escola por meio de transmissão de conhecimentos e valores modernos, provoque mudanças e atualizações na vida indígena [...]. (GERSEM, 2011, p. 221).

Por isso, nosso interesse em ir às áreas indígenas, a fim de interagir com o processo educativo e a troca de saberes com os líderes da comunidade, os tu'isas e os professores, destacando a importância desses povos no âmbito escolar.

\section{As escolas do rio Marau}

As primeiras práticas de educação formal foram iniciadas pelos jesuítas no período da colonização do Brasil em 1549. Segundo Marreiro (2007, p.15) na década de 60 foram implementadas escolas nas várias comunidades da etnia Satere-Mawe no rio Marau, primeiro foi coordenado pelo Instituto de Educação Rural do Amazonas - IER-AM e, em seguida, pela Secretaria Municipal de Educação - SEMED, com professores nãoíndios, ocorrendo então a imposição da língua portuguesa que servia de aquisição da cultura nativa e continuação do processo de dominação e domesticação dos indígenas. Nas últimas décadas, com formação de professores indígenas o ensino passou a ser ministrado por professores da etnia.

Atualmente, a figura do puruwei em língua satere-mawe e professor em língua nacional, marca sua presença ao manifestar a necessidade da comunidade em interagir com a cultura classificada como a do não-índio. Segundo Esteves (2007, p.115) Esse processo de interação acontece como ação mediadora do educador que tem o significado de ser o instrumento pedagógico de ressignificação dos valores 
culturais.

$\mathrm{Na}$ Escola, o cotidiano é expresso na sala de aula através da ação pedagógica do professor que assume, de fato, seu papel de responsável por todo andamento das atividades escolares. Como escola representa um espaço importante na aldeia, o puruwei é então um dos atores sociais mais respeitados da comunidade, por ser ele o detentor do status de quem conhece o mundo dos asiag pot'u (brancos ou não-índios) e por esse motivo aprendeu um pouco daquilo que os asiag pot'u conhecem e que o povo deseja se apropriar. Assim o puruwei possui a consciência do significado do seu papel e da sua responsabilidade perante os anseios da comunidade e procura se autodefender de políticas que possam prejudicar o povo.

As escolas das duas comunidades identificam-se como a maioria das escolas indígenas no Brasil, a esperança de se libertar de antigas políticas colonizadoras que ainda se articulam desde sua formação. Infelizmente, a escola que deveria servir para fortalecer a cultura, serve ainda hoje, para sustentar o mesmo projeto colonizador de caráter de imposição ideológica sobre o grupo. Como exemplo desta prática, observe-se que as políticas que envolvem a escola Satere-Mawe, ainda são decididas de maneira impositiva através das políticas aplicadas pela Secretaria Municipal de Educação SEMED e Secretaria de Estado de Educação - SEDUC.

Segundo os professores e os tu'isas, o ensino escolar em salas multisseriadas do ensino fundamental apresenta-se como uma nova maneira de ordenar a vida na comunidade, passando a constituir um novo espaço em que o fenômeno educativo impôs suas regras para se aprender e ensinar, com conhecimentos sistematizados pelo professor. Isso implicou o surgimento de uma lógica social para atender com mais equidade às relações existentes com o não-índio. No entanto, quando se trata da dimensão pedagógica, os professores reforçam a ideia de construção de uma pedagogia de ação, implicando um sujeito comprometido com sua realidade, pois temem que a escola Satere-Mawe possa estar reforçando um ensino que remeta o sujeito para fora de sua realidade.

Trazendo à tona o significado daquilo que Almeida (1997, p.29) afirma sobre o sinônimo de civilização: "o conceito de civilização estará sempre associado a uma ação autoritária". Dentro desse contexto, o processo histórico da formação das escolas está estruturado numa relação de força e de poder em que as diretrizes educacionais são instituídas por alguns brancos. (WEIGEL, 2000). Seguindo este raciocínio as autoras afirmam, a seguir, que

\footnotetext{
a escola para os índios é a mais antiga do Brasil e as primeiras iniciativas escolares são do período colonial: ao tomarem posse das terras habitadas pelos povos indígenas, uma das primeiras ações dos europeus foi organizar e impor aos nativos um aparato educativo de acordo com os padrões ocidentais, sendo a escola um deles (BERGAMACH; SILVA, 2007, p. 126).
}

Então, podemos inferir que é algo desafiador produzir novas práticas sobre a realidade da escola indígena no Brasil que talvez seja parecida com a de muitas escolas de zona rural, mas ainda assim, se percebe a resistência para alcançar um modelo de ensino capaz de reconhecer os valores culturais presentes no contexto local. Percebemos isso, no acolhimento do tu'isa, dos professores e comunitários em permitirem e participarem das oficinas pedagógicas, nos anos de 2016 e 2017. 


\section{Comunidade São Pedro no rio Marau}

Iremos elencar alguns aprendizados e descobertas a partir das experiências construídas nesta comunidade. Ao aproximarmos do lugar, presenciamos uma partida de futebol promovida pelos comunitários e o tu'isa, neste momento, foi possível acompanhar as recreações das crianças e jovens indígenas. Em seguida, realizamos uma boa conversa com e o tu'isa Paulo Oliveira Sateré e os professores Sergio, Aliomar e Claudete que ficaram otimistas com a possibilidade de ampliar suas práticas pedagógicas, quando expusemos os objetivos do projeto de extensão, que pretende atender às demandas apuradas em pesquisa de campo em 2015.

Na escola Pysye hyeretete que significa "início da educação", foram realizadas duas rodas de conversa: a primeira tratou sobre a Formação Social e Histórica dos SatereMawe. A exposição foi dinâmica e de boa compreensão por parte dos indígenas, com a ilustração de um mapa do tempo, descrevendo a região onde a etnia habitava, correspondendo os rios Tapajós, Madeira e as Ilhas Tupinambaranas no rio Amazonas e por conta do contato conflituoso com os europeus, abandoaram as terras da várzea, de solo mais fértil e foram ocupar as cabeceiras dos rios Marau e Andirá.

A segunda tratou sobre o Mito do Neke'y, baseado nas narrativas de Dona Maria Lopes Trindade Sahu Uggé (1990, p.12) "totem é também fixada a memória da origem dos clãs (narrada no mito do Purantin) de quando os primeiros Mawe foram classificados com nomes de bichos e de plantas". A narrativa destaca o medo desta etnia ao se defrontar com a onça que deseja devorar as pessoas. O mito Neke'y, mito de origem que dá continuidade ao mito cosmogônico de maneira que abre possibilidades de reconhecer o lugar ocupado pelos Satere-Mawe. Assim, fundamenta-se o espaço histórico e identitário de cada clã.

\section{Comunidade Terra Nova no Rio Marau}

Nesta comunidade, apresentamos ao Tu'isa Bernardo Moi e a sua esposa Cristina Moi as propostas do projeto e marcamos a data do segundo encontro para a realização das oficinas em 2017. Eles expuseram seu interesse e concordaram com as propostas apresentadas e estavam dispostos a colaborar na realização das atividades.

O contexto local foi promissor para o desenvolvimento do trabalho e da interação com a escola Wanteru que em português significa "vagalume". Neste encontro, foram organizadas as oficinas e definimos as seguintes atividades: noções básicas de gêneros textuais, formação sobre as práticas culturais e construção étnica SateréMawé, Ritual do Sapó (warana) e narrativas orais do Mito da Terra e do Mito da Água. Vale destacar que durante a exposição o Tu'isa que também é professor, realizava a tradução oral em língua satere-mawe ao público presente.

$\mathrm{Na}$ oficina de produção textual, foi realizada uma discussão sobre gêneros orais e escritos e sua importância para vida prática. Os gêneros textuais mais utilizados pela etnia são a conversa, narrativa dos mitos, narrativa das lendas, cantorias, reza e aconselhamentos, entre outros. Então, propondo uma compreensão de que o sujeito aprende a falar sua língua materna através de textos materializados em gêneros textuais e, neste processo, os membros da comunidade, no processo de interação comunicativa, constroem e transmitem conhecimentos. Tal como frisa Marcuschi (2008, p.193-194) "[...] os domínios discursivos operam como enquadres globais de superorganização comunicativa, subordinado práticas sociodiscursivas orais e 
escritas que resultam em gêneros".

Na segunda etapa, foi trabalhado o gênero escrito (requerimento), pois levamos em consideração sua importância para os professores e os tu'isas que precisam se comunicar na forma escrita com as instituições dos não-índios como: prefeitura, as secretarias e outros órgãos e entidades na sede de Maués. Para Bakhtin (2011, p.285) "Quanto melhor dominamos os gêneros tanto mais livremente os empregamos, tanto mais plena e nitidamente descobrimos neles a nossa individualidade (onde isso é possível e necessário)".

Participaram das atividades, adolescentes e idosos devido a cultura desta etnia não excluir qualquer geração das atividades lá realizadas, apesar de nosso público alvo ser os professores e tu'isas. Com a inclusão destes membros, achamos relevante realizar a certificação dos alunos e dos comunitários que foram acolhidos no processo de formação.

Durantes as oficinas, o ritual do Sapó era, comumente, realizado. As atividades da noite ficaram na responsabilidade do Tu'isa, na tentativa de fortalecer as práticas de narrativas orais que eram realizadas por seus ancestrais. Segundo ele "na etnia sempre existiram os idosos, que são sábios de nossa cultura, que conhecem as histórias e mitos da etnia. No início da noite, ocorria a reunião com os membros da comunidade em que estes sábios contavam as histórias do nosso povo para as gerações mais jovens, a fim de manter viva a nossa cultura. Só que com o passar do tempo, foi sendo deixada de lado essa tradição. Por isso, presenciamos que nossas crianças e jovens não conhecem muito de nossos mitos e tradições. Nosso trabalho de líder da comunidade pretende fortalecer essas narrativas para que os membros mais jovens possam ser agentes multiplicados de nossa tradição."

Na oficina O Mito da Origem da Terra (Yi Sa'awy Etiat), a professora Cristina fez a narração em língua satere-mawe. Ela explicou que foi o sábio Brito de Oliveira da comunidade kuruatuba quem contou para eles este mito. Durante a narrativa, nós na posição de não-índios, não compreendíamos quase nada, mas percebíamos a importância da língua como patrimônio cultural de um povo e desta etnia.

Segundo Teixeira (2005, p. 91),

[...] (a) situação linguística do povo sateré-mawé tem como base a concepção, defendida por antropólogos e linguistas, de que a língua se configura como um importante instrumento de construção da cultura e da identidade de uma população. A identificação do modo como os Sateré-Mawé estão usando esse instrumento de comunicação e expressão cultural permite a formulação de entendimentos sobre suas estratégias simbólicas e políticas, para viver as interações com os outros grupos da sociedade maior.

Essa citação corrobora com a afirmação de Rodrigues (2014) de que a linguagem, independentemente da etnia que a pratica, é o meio pelo qual se produz cultura. Representa-se com a linguagem o sentido e a vida em sociedade. É indispensável em todas as culturas a comunicação de tudo o que se aprende e que se pode ensinar, visto que todo sujeito comunica com o seu grupo social diante do sistema linguístico que sustenta as relações sociais.

No livro Uma viagem pelo Brasil nos anos de 1817 e 1820, os autores Spix e Martius (1981) detalharam em um capítulo, a narrativa da viagem na Barra do Rio Negro ao 
Rio Madeira em que descrevem o contado com as missões e com várias tribos indígenas entre elas: os Mundurucus, Maués, Uainumás, Jumás, Parintintins, Apiacás, etc. Detalham que enquanto as demais tribos ensinam sua língua sem qualquer dificuldade, já os maués possuem uma crença que proíbe que eles ensinem a outros povos sua língua materna, fato este detalhado na citação abaixo:

A sua língua é muito sonora e difícil de entender-se. Foi impossível obter alguém que me pronunciasse as palavras que pedi. $O$ missionário ponderoume que eles se recusam por medo de feitiço, pois apesar de terem vaga ideia da divindade. São muito inclinados a crer no poder dos demônios maus, a quem, entre outras coisas, atribuem também a morte [...] (SPIX; MARTIUS, 1981, p.282).

É provável que, mesmo depois de ter decorrido mais dois séculos da observação dos autores acima, ainda possa existir uma certa resistência dos Satere-Mawe em ensinar ao não-índio a sua língua materna. Temos como exemplo atual, o trabalho de pesquisa do professor Alio Sateré e Cledalto Sateré acadêmicos do Curso de licenciatura indígena da UFAM, que realizaram uma etapa do seu projeto na escola Estadual São Pedro em Maués no ano de 2017, aplicando uma oficina de noções básicas de língua satere-mawe aos alunos e aos professores da rede pública de ensino. Segundo os pesquisadores, "a realização desta etapa do projeto foi muito criticada por vários membros de nossa etnia", isso deve decorrer dessa crença de maldição de morte que os autores Spix e Martius (1981) citaram, traduzindo, com isso, uma das expressões da cultura imaterial desta etnia.

Como afirma Teixeira (2005, p. 96) "O idioma Sateré-Mawé é mais falado na área do Marau que nas demais (Andirá, Uaicurapá e Koatá-laranjal". Isso se fortalece ainda mais nas comunidades mais próximas às cabeceiras ao longo destes rios, por serem mais distantes e pouco sofrem as influências culturais do não-índio e, por isso sua língua é mais preservada. Percebe-se que as mulheres jovens e, principalmente, as idosas da etnia são as protagonistas de sua língua, pois muitas falam apenas a língua satere-mawe não se importando em aprender e nem se comunicar em língua nacional.

A última oficina intitulada narrativa do Mito da Origem da Água (Y'y Sa'awy Etiat) em que o professor Enison Michiles pediu que todos os comunitários sentassem em forma de círculo, revivendo o cotidiano de seus ancestrais. Ao final de cada leitura o tu'isa traduzia e explicava aos presentes a interpretação dos mitos para que todos pudessem compreender e guardar na memória, para depois, propagar estas histórias míticas, ou seja, esta crença aos seus familiares e vizinhos, como uma atitude de preservar a identidade cultural dos Satere-Mawe.

\section{Reflexões das práticas vivenciadas nas oficinas pedagógicas}

Foram realizadas entrevistas com os professores que detalharam as experiências mais significativas de suas práticas pedagógicas, com o objetivo de compreender o cotidiano da escola indígena para que, nas futuras atividades de extensão, fossem direcionadas mais ações que favoreçam o ensino e aprendizagem das crianças e jovens, como defendem as autoras Moita e Andrade (2009, p.274) "[...] Mais que levar ideias prontas, queríamos saber o que eles e elas, como atores de seu cotidiano, tinham a nos falar e o que poderíamos juntos construir, durante as oficinas 
pedagógicas." Confira, a seguir, as três práticas de ensino mais recorrentes nas salas multisseriadas das comunidades:

A primeira foi atividade de produção escrita com desenhos ilustrativos sobre o cotidiano da comunidade, como: trabalho na roça, pescaria, ritual do sapó, tomar banho no rio, entre outros e ensino da gramática da língua satere-mawe.

O professor Alio Sateré expôs que "o ensino da escrita, torna-se mais compreensível para os alunos quando trazemos temas sobre suas vivências, aproximando assim a compreensão de sua língua materna na forma escrita sobre assuntos da realidade local".

Este processo tem a intenção de modificar a experiência educativa que a maioria dos professores da área indígena teve em sua formação, ao aprender primeiro a escrita da língua portuguesa. Sobre o esboço da situação sociolinguística e educacional dos Satere-Mawe no rio Andirá Silva (2007) aponta que os professores tiveram o contato com a escrita em sua língua materna a pouco tempo, considerando que a escrita e a leitura sempre ocorreram em língua nacional. "Esses professores sofreram ao serem alfabetizados pela obrigação de aprender uma língua imposta num claro processo onde a língua materna serviria apenas de veículo de transição para o aprendizado" (SILVA, 2007, p.87).

Sobre este contexto, percebe-se que, atualmente, há uma mudança de atitude dos professores em priorizarem no ensino da escrita em língua satere-mawe e, depois uma contextualização com a língua portuguesa. Este processo de ensino e aprendizagem toma uma direção intercultural e bilíngue que contribui na interação social dos Satere-Mawe, facilitando a sua comunicação na zona urbana seja para estudar, seja para resolver suas necessidades pessoais, assim como também na alfabetização e no acesso à forma escrita, considerando, que os povos indígenas têm como manifestação linguística primordial, a oralidade.

A segunda, foi atividade de leitura e de interpretação de texto sobre os mitos, os cantos, o cultivo do guaraná, a caça, a pesca, entre outros. Esta prática de ensino e aprendizagem sobre os aspectos da cultura local propicia um processo pedagógico que fortalece não só a compreensão e a interpretação de texto escrito, como também na disseminação dos mitos e das crenças que sustentam a identidade desta etnia. Para Geertz (1989, p.150) "[...] O estudo da cultura, a totalidade acumulada de tais padrões, é, portanto, o estudo da maquinaria que os indivíduos ou grupos de indivíduos empregam para orientar a si mesmos num mundo que de outra forma seria obscuro". Esta posição defendida por Geertz deixa claro como os Satere-Mawe buscam preservar e fortalecer suas tradições e, com isso, significarem no mundo.

A terceira foi o ensino de matemática como o uso de artesanatos da tradição como: arco, flecha, tipiti, cuia, peneira, cesto, colares, remos e anéis. Os professores consideram este processo bastante construtivo e simbólico para os alunos compreenderem as formas geométricas, as medidas e operações matemáticas. Sobre isso, pode-se inferir que a linguagem é feita de símbolos que promovem a comunicação entre as pessoas de um grupo social, portanto o estudo da matemática através dos artesanatos promove o que Geertz (1989, p. 93) afirma "[...] os significados só podem ser "armazenados" através de símbolos".

As experiências pedagógicas dos professores contribuíram para apontar novas possibilidades de lidar com espaço escolar com práticas tradicionais que influenciam diretamente $o$ ato de ensinar e apreender. Desta maneira, confirma-se a dimensão 
histórica deste povo pelo fato de construir atitudes inerentes ao ser humano, enquanto um ser que age e pensa através de sua cultura.

\section{A relevância das práticas adotadas: resultados e discussões}

O desafio em realizar atividades de extensão que possam, efetivamente, contribuir com o ensino e aprendizagem na etnia Satere-Mawe foi e é um grande desafio para nós professores pesquisadores que atuamos longe da área indígena. A partir da experiência vivenciada nestas comunidades, achamos relevante realizar uma reflexão, em que foram registrados os anseios e os comentários dos participantes, para que o leitor deste artigo tenha a possibilidade de construir propostas que possam contribuir com a escola indígena. Não apenas indo à comunidade e colhendo material para suas inquirições, mas, principalmente, trazendo um retorno com possíveis soluções para uma escola indígena de qualidade. Leia a seguir os comentários mais recorrentes:

Primeiro, "Foi muito importante para nós, professores da área indígena estas oficinas precisávamos de formações para fortalecimento de nossa prática pedagógica"; "Os conteúdos falam sobre nossas vivências trazem uma compreensão mais ampla para nossa realidade, considerando que são raras as semanas pedagógicas por aqui."Esta afirmação evidencia os anseios desses liderem por formação continuada que atenda as demandas educacionais da escola indígena. Com bem posiciona a autora Calderano (2017, p. 59) em que aponta sobre os desafios do

\footnotetext{
[...] trabalho docente desenvolvido isoladamente, por mais competente que seja, não daria conta de enfrentá-los devidamente. Tampouco, o trabalho cooperado, se for apartado da realidade concreta que o circula, também não daria conta de atingir objetivos educacionais emancipatórios. Nem mesmo o amplo conhecimento, se não se apoiar em sua mediações didáticopedagógicas, muito pouco pode alcançar em termos de resultados favoráveis à ampliação de conhecimento teoricamente relevante e socialmente significativo.
}

Segundo, "O compartilhamento destes saberes foi muito produtivo para nós, muitos pesquisadores e doutores vêm aqui, querem saber de nossa cultura, depois vão embora e poucos voltam para mostrar seus trabalhos ou contribuir com a nossa comunidade". Como uma atitude ética, é importante que se dê um retorno, um dizer ou uma resposta ao campo de trabalho. Segundo Moita e Andrade (2009, p.271) que trazem à tona uma crítica sobre uma espécie de injustiça cognitiva com os saberes das comunidades tradicionais, onde cita o exemplo de colonização cultural que ocorreu na índia [...] onde "a ciência se apropria e reserva para si a patente dos saberes camponeses" sem que "haja um reconhecimento espitérmico do estatuto desses saberes".

Terceiro, "Gostaríamos que este projeto fosse realizado todos os anos. Foi bom compartilhar com vocês também um pouco de nosso cotidiano, sejam sempre bemvindos aqui em nossa comunidade". Ao vivenciar o cotidiano dos Satere-Mawe, podemos afirmar que este contato nos enrique e nos humaniza diante de um local tão afastado da cidade, em que mostra uma luta perene para manter-se como etnia fortalecida em suas práticas culturais. Segundo Uggé (1995, p10). 
Os Sateré-Maué, por parte de que teve contato com eles, são apreciados como pessoas inteligentes, de memória muito viva capazes de interpretar e conhecer o pensamento e a vontade do outro; hábeis imitadores nas atividades práticas, dedicados e rápidos, possuem forte desejo de conhecer e saber, além de cordiais e hospitaleiros com que inspiram confiança.

Enfatizamos aqui a importância de pesquisar e identificar problemas e os anseios dos sujeitos do processo investigativo para, em seguida, retornar com prática extensionista através de ações que possam atender as demandas da comunidade. $\mathrm{E}$, em nosso caso, trabalhamos as oficinas numa perspectiva interativa com os professores, tu'isas e comunitários, resultando nas reflexões acima descritas.

\section{Considerações finais}

A tarefa que propôs este artigo partiu da tentativa de contribuir com os professores e tu'isas da área indígena, elencando informações que possam construir um novo olhar sobre as práticas culturais da etnia Satere-Mawe através do ensino na escola. Podemos considerar que durante a nossa presença nas comunidades São Pedro e Terra Nova, foi possível perceber a importância dessa formação pedagógica não só para os participantes, mas também para nós que interagimos com os saberes locais.

Vale destacar que, apesar das mudanças nas legislações sobre a educação indígena, na prática, muito tem que ser feito para atender as necessidades e interesses da comunidade. Não podemos pensar em construir uma escola indígena diferenciada, sem não lutarmos, realmente, por sua melhoria e contribuir com o contexto histórico desses povos em suas comunidades e também na diversidade cultural do Amazonas. Por isso, é através da cultura, manifestada na escola que se percebe o quanto a etnia Satere-Mawe é capaz de construir conhecimento dentro e fora dela. Esta atitude corrobora com as pesquisadoras Bergamasch; Silva (2007) que defendem a escola do índio que é diferente da escola para o índio, sendo que esta última sempre foi imposta pelos não índios.

\section{Referências}

ALMEIDA, Rita Heloísa de. O Diretório dos índios: um projeto de "civilização" no Brasil do Século XVIII. Brasília: Editora da Universidade de Brasília, 1997.

ANDRÉ, Marli Eliza Dalmazo Afonso de. Etnografia da prática escolar. Campinas: Papirus, 1995.

BAKHTIN, Mikhail Mikhailovitch. Estética da criação verbal. 6. ed. São Paulo: WMF Martins Fontes, 2011.

BERGAMASCH, Maria Aparecida; SILVA, Rosa Helena Dias da. Educação escolar indígena no Brasil: da escola para índio às escolas indígenas. Agora, Santa Cruz do Sul. v. 13, n.1, p.124-150, jan./jun. 2007.

CALDERANO, Maria Assunção. 0 estágio curricular e a docência compartilhada: na perspectiva do realismo crítico. Curitiba: Appris, 2017. 
CUNHA, Maria Manuela Ligeti Carneiro da. Cultura com aspas: e outros ensaios. [S. l.: s.n.], 2009.

DOSSIÊ da Agenda 2030. Com Ciência: Revista Eletrônica de Jornalismo Científico, n. 208, jun./2019. Disponível em http://www.comciencia.br/o-que-eagenda-2030-das-nacoes-unidas-e-quais-sao-os-objetivos-de-desenvolvimentosustentavel. Acesso em: 5 nov. 2019.

ESTEVES, Carlos Dinelli. Prática Pedagógica e Construção de Identidade SateréMawé: Escola Wanteru - ponte entre o passado e o presente. 2008. 137 f. Dissertação (Mestrado) - Curso de Educação, Faced, Universidade Federal do Amazonas, Manaus, 2008. Cap. 3. CD-ROM.

GEERTZ, Clifford. A interpretação das culturas. Rio de Janeiro: Copyright, 1989.

LÉVI-STRATUS, Claude, O pensamento selvagem, São Paulo: Papirus 1989.

LUCIANO, Gersem José dos santos. Educação para manejo e domesticação do mundo: entre a escola ideal e a escola real: os dilemas da educação indígena no Alto Rio Negro. Universidade de Brasília-DF, 2011.

MARCUSCHI, L. A. Produção textual, análise de gêneros e compreensão. São Paulo: Parábola Editorial, 2008.

MARTIUS; SPIX. Viagem pelo Brasil 1817 a 1820. São Paulo: Universidade de São Paulo, 1981.

MARREIRO, Telma de Lima da Cunha. Projeto Político Pedagógico, Étnico, Educação e Cultura Sateré-Mawé. Manaus - UFAM, 2007.

MOITA, Filomena Maria Gonçalves da Silva Cordeiro; ANDRADE, Cézar Bezerra. Ensino-pesquisa-extensão: um exercício de indissociabilidade na pós-graduação. Revista Brasileira de Educação, v.14, n. 41, maio/ago. 2009.

RAMOS, Francicleo Castro. Socialização e cultura escolar no Brasil. Revista Brasileira de Educação, v. 23, ano 2018.

RODRIGUES, Aryon Dall'Igna. Biodiversidade e diversidade etnolinguística na Amazônia. Ecolinguística: Revista Brasileira de Ecologia e Linguagem, Brasília, DF, v. $1, \quad$ n. $\quad 1, \quad 2015 . \quad$ Disponível em: https://periodicos.unb.br/index.php/erbel/article/view/9966. Acesso em: 5 nov. 2019.

SILVA, Raynice Geraldine Pereira da. Esboço sociolinguístico Sateré-Mawé. Tellus, ano 7, n. 13, out. 2007.

TEIXEIRA, Pery. Sateré-Mawé: retratos de um povo indígena. Manaus: EDUA, 2005.

UGGÉ, Henrique. Bonitas histórias Sateré-Mawé. Manaus: SEDUC, 1990.

WEIGEL,Valeria Augusta Cerqueira Medeiros de. Escolas de branco em malokas de índio, Manaus: EDUA, 2000. 
Recebido: 23/04/2021

Aprovado: $17 / 08 / 2021$

Como citar: SERRA, V. J. A.; ESTEVES, C. D. Formação de Professores Indígenas, contextualizando o ensino às práticas culturais da etnia Satere-Mawe. Educitec - Revista de Estudos e Pesquisas sobre Ensino Tecnológico, v. 7, e172221, 2021.

Contribuição de autoria:

Vilma de Jesus de Almeida Serra: Conceituação, curadoria de dados, investigação, administração de projeto, escrita (rascunho original) e escrita (revisão e edição).

Carlos Dinely Esteves: Metodologia, escrita (rascunho original), supervisão e validação.

Direito autoral: Este artigo está licenciado sob os termos da Licença Creative Commons-

Atribuição 4.0 Internacional

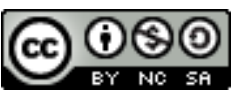

